\title{
Correction: Aung Zaw Win, Renal Cell Carcinoma Metastasis to the Gallbladder Detected by FDG-PET/CT
}

\author{
Aung Zaw Win
}

Corrections to article "Renal Cell Carcinoma Metastasis to the Gallbladder Detected by FDG-PET/CT", by Aung Zaw Win, published in Vol. 6, No. 6, 2014, p482-486, doi: http://dx.doi.org/10.14740/jocmr1886w. The author would like to add a contributing author in the second position of author list, the new author list should read as follows.

Aung Zaw Win ${ }^{\mathrm{a}, \mathrm{c}}$, Carina Mari Aparici ${ }^{\mathrm{b}}$

aDepartment of Radiology, San Francisco VA Medical Center, 4150 Clement Street, San Francisco, CA 94121, USA

${ }^{b}$ Department of Radiology, University California San Francisco (UCSF), 500 Parnassus Ave, San Francisco, CA 94143, USA

'Corresponding Author: Aung Zaw Win, Department of Radiology, San Francisco VA Medical Center, 4150 Clement Street, San Francisco, CA 94121, USA. Email: aungzwin@gmail.com

This work was performed at the San Francisco VA Medical Center, 4150 Clement Street, San Francisco, CA 94121, USA

Manuscript accepted for publication February 01, 2015

Department of Radiology, San Francisco VA Medical Center, 4150 Clement

Street, San Francisco, CA 94121, USA. Email: aungzwin@gmail.com

doi: http://dx.doi.org/10.14740/jocmr2146e 